\title{
Sử dụng FRP để phục hồi khả năng chịu tải của sàn bê tông cốt thép bị cháy
}

\author{
Võ Bá Huy ${ }^{1}$, Đoàn Văn Đẹt ${ }^{2}$, Cao Văn Vui ${ }^{3}$
}

${ }^{1}$ Khoa Kỹ thuật Hạ tầng Đô thị, Trường Đại học Xây dựng Miền Tây

${ }^{2}$ Trung tâm Thí nghiệm Xây dựng và Môi trường, Trường Đại học Xây dựng Miền Tây

${ }^{3}$ Khoa Kỹ thuật Xây dựng, Trường Đại học Bách Khoa - Đại Học Quốc Gia Tp. Hồ Chí Minh

\begin{tabular}{|c|c|}
\hline TƯ KHOÁ & TÓM TẮT \\
\hline Sàn bê tông cốt thép & Bài báo này trình bày kết quả nghiên cứu thực nghiệm khả năng chịu tải của sàn bê tông cốt thép sau khi \\
\hline Cháy & cháy có và không có gia cường bằng Fiber Reinforced Polymer (FRP). Thí nghiệm được thực hiện trên 9 \\
\hline \multirow[t]{5}{*}{ FRP } & thành 2 nhóm có thời gian cháy của mỗi nhóm lần lượt là 45 và 75 phút. Sau khi cháy, hai mẫu của mỗi \\
\hline & nhóm được gia cường bằng FRP. Kết quả thí nghiệm cho thấy màu sắc các mẫu này chuyển từ màu xám \\
\hline & của bê tông trước khi cháy sang màu vàng nhạt, hồng nhạt và xám đen sau khi cháy. Sự suy giảm khả \\
\hline & và 1 lớp FRP cho các sàn bị cháy lần lượt làm tăng 46,6 \% và 65,4 \% khả năng chịu tải cực hạn so với sàn đối \\
\hline & chứng. \\
\hline
\end{tabular}

\section{KEYWORDS}

Reinforced concrete slab

Fire

Load-carrying capacity

FRP retrofit

\begin{abstract}
This paper presents the experimental results on the ultimate strength of fire-exposed reinforced concrete (RC) slabs with and without Fiber Reinforced Polymer (FRP) strengthening. The experiments were carried out on 9 RC slab specimens. One specimen was not subjected to fire to use as the control specimen. Other 8 specimens were divided into 2 groups which were subjected to fire with durations of 45 and 75 minutes. After exposing to fire, 2 specimens of each group were strengthened by FRP. The results showed that the color of these specimens changed from gray color of normal concrete to light yellow, light pink, black gray after exposing to fire. The strength of fire-exposed specimens reduced less than $10.5 \%$ probably because the steel reinforcement recovered its strength. Strengthening with $1 / 2$ and 1 FRP layer increased the strength of fire-exposed specimens by $46.6 \%$ and $65.4 \%$, respectively, compared to that of the control specimen.
\end{abstract}

\section{Giới thiệu}

Trên thế giới, nhiều trận hỏa hoạn đã xảy ra ở các công trình xây dựng, gây ra những tổn thất về người và của. Điển hình như vụ cháy tòa nhà Grenfell Tower ở Anh (Hình 1 ). Như có thể thấy từ Hình 1 , toàn bộ tòa nhà ngập chìm trong lửa. Một ví dụ điển hình khác là vụ cháy tòa nhà Plasco ở Iran. Hình 2a thể hiện tòa nhà Plasco đang bị cháy và đội cứu hỏa đang dập đám cháy. Mặc dù vậy, tòa nhà vẫn bị lửa làm sập hoàn toàn theo phương thẳng đứng như Hình $2 \mathrm{~b}$.

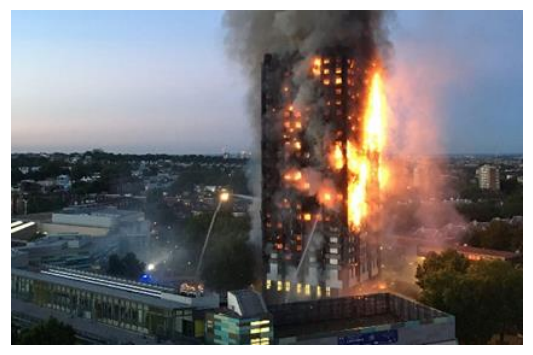

Hình 1. Công trình Grenfell Tower (Anh) bị cháy (nguồn: https://www.standard.co.uk/news/crime/fraudster-took-nearly90000-from-council-by-claiming-to-be-grenfell-tower-squatter-whohelped-a4298556.html)
Ở Việt Nam, nhiều vụ cháy cũng đã xảy ra, làm thiệt hại về người và tài sản. Năm 2002, vụ cháy ở toà nhà Trung tâm Thương mại quốc tế ITC (quận 1, TP. Hồ Chí Minh) khiến 60 người tử vong. Gần đây, vụ cháy ở chung cư Carina Plaza (Hình 3) cũng đã cướp đi sinh mạng của nhiều người và hư hại kết cấu ở những mức độ khác nhau.

Hỏa hoạn đối với công trình luôn là một vấn đề được cộng đồng quan tâm và lo lắng. Khi bị cháy, kết cấu sẽ bị hư hại ở những mức độ từ nhẹ đến nặng khác nhau. Đánh giá mức độ ảnh hưởng của hỏa hoạn đối với kết cấu luôn làm đau đầu các nhà nghiên cứu vì tính chất phức tạp của lửa. Riêng về lĩnh vực kết cấu bị cháy, nhiều nhà nghiên cứu cũng đã có những công trình đã được công bố; tuy nhiên, vẫn còn rất nhiều vấn đề còn chưa được làm sáng tỏ. Bên cạnh đặc điểm ảnh hưởng phức tạp của lửa đối với kết cấu, các thí nghiệm về kết cấu bị cháy thường rất tốn kém vì thí nghiệm cháy phải được thực hiện trước, và sau đó là thí nghiệm khả năng chịu lực của kết cấu bị cháy. Như vậy có thể thấy rằng, khi nghiên cứu về kết cấu bê tông cốt thép (BTCT) nói riêng và kết cấu nói chung chịu tác động của lửa, khối lượng công việc và sự phức tạp có thể gấp đôi.

Sàn BTCT là một trong những cấu kiện bị ảnh hưởng nặng do tác động trực tiếp của lửa lên bề mặt phía dưới sàn. Nhiều công trình 
nghiên cứu về mô phỏng sàn BTCT bị cháy đã được nhiều tác giả thực hiện và công bố trên các tạp chí quốc tế. Huang [1] phát triển mô hình để xem xét ảnh hưởng của sự bong tách của bê tông đối với ứng xử của sàn BTCT bị cháy. Tác giả đã phân tích 16 trường hợp với mức độ bong tách bê tông do các tác động cháy khác nhau. Tác giả kết luận rằng hiệu ứng màng (membrane effect) của sàn đóng vai trò quan trọng trong việc giảm ảnh hưởng của việc bong tách đến ứng xử của sàn bê tông dưới tác dụng của lửa. Lim và cộng sự [2] thực hiện nghiên cứu mô phỏng ứng xử của sàn BTCT hai phương dưới tác dụng của lửa bằng phần mềm SAFIR. Mô hình được phát triển trên phần mềm SAFIR và được kiểm chứng bằng các kết quả thí nghiệm. Sau đó, mô hình được sử dụng để phân tích và kết quả cho thấy rằng sàn hai phương có khả năng chịu lửa tốt nếu chúng biến dạng theo kiểu uốn cong hai phương (double curvature) và có hiệu ứng màng. Huang và cộng sự [3] phát triển mô hình phần tử hữu hạn lớp phi tuyến để mô phỏng ứng xử của bản BTCT bị cháy sử dụng lý thuyết tấm Mindlin/Reissner, các đặc trưng phi tuyến hình học và phi tuyến vật liệu. Các yếu tố như sự truyền nhiệt, nứt và sự phá hoại nén của bê tông, thay đổi đặc trưng cơ học của vật liệu với nhiệt độ cháy được đưa vào mô phỏng. Thuật toán Lagrangian cũng được sử dụng trong mô phỏng. Kết quả phân tích sàn BTCT hình chữ nhật cho thấy mô hình phần tử hữu hạn lớp phi tuyến có thể mô phỏng được hiệu ứng màng của sàn trong điều kiện cháy. Sau đó, Huang và cộng sự [4] sử dụng mô hình đã được họ phát triển trước đó [3] để mô phỏng sàn BTCT kê bốn cạnh. Lim và cộng sự [5] nghiên cứu mô phỏng sàn một phương bị cháy với các điều kiện liên kết gối giản đơn và liên kết ngàm, chiều dài sàn là $5 \mathrm{~m}$, chịu tải phân bố đều bằng phần mềm SAFIR. Kết quả cho thấy rằng sàn với gối giản đơn có khả năng chịu lửa kém hơn sàn có liên kết ngàm. Moss và cộng sự [6] mô phỏng ứng xử của sàn BTCT hai phương chịu tác dụng của lửa theo tiêu chuẩn ISO 834 kéo dài trong 1 giờ và 4 giờ kể cả ảnh hưởng trong thời gian 2 giờ để nhiệt độ giảm xuống đến nhiệt độ xung quanh. Kết quả nghiên cứu cho thấy bê tông và cốt thép dưới sàn có nhiệt độ tăng cao trước khá nhiều so với bê tông và cốt thép mặt trên. Điều này dẫn đến xu hướng làm sàn bị uốn cong nhưng lại bị cản trở bởi các liên kết biên. Kết quả là mô men uốn trong sàn được phân bố lại. Khi nhiệt độ của thép lưới dưới vượt quá $300^{\circ} \mathrm{C}$, cường độ chảy dẻo của thép giảm khi nhiệt độ tiếp tục tăng, và từ đó làm giảm khả năng chịu tải của sàn. Huang và cộng sự [7] cải tiến phần tử lớp để mô phỏng tấm bị cháy bằng cách sử dụng chiều dày danh định của sàn làm chiều dày của phần tử sàn và sử dụng hệ số để hiệu chỉnh độ cứng của bê tông để xét đến yếu tố trực hướng của sàn. Thuyết bền biến dạng cực đại được sử dụng để mô phỏng bê tông. Mô hình được kiểm chứng bằng các kết quả thực nghiệm với mức độ chính xác chấp nhận được. Yu và Huang [8] phát triển phần tử lớp phi tuyến với sự không liên tục yếu (weak discontinuity) được lồng vào để mô phỏng phá hoại kéo lũy tiến của sàn BTCT khi biến dạng lớn. Mô hình được kiểm chứng với kết quả thí nghiệm và có thể được sử dụng để mô phỏng khả năng chịu tải và xác định sự phát triển vết nứt của sàn BTCT bị cháy. Wang và cộng sự [9] kiến nghị một mô hình để phân tích sàn BTCT chịu tác dụng của nhiệt độ cao. Trong mô hình này, độ ẩm và quy luật cấu thành và truyền nhiệt của bê tông được xem xét. Một số kết luận được rút ra như sau.
Độ ẩm có vai trò quan trọng trong việc phân bố nhiệt độ trong sàn và từ đó có ảnh hưởng đến ứng xử của sàn khi chịu tải. Vì vậy, độ ẩm cần được đưa vào trong phân tích khả năng chịu lửa của sàn BTCT. Mô hình có thể mô phỏng khả năng chịu lửa với mức độ chính xác phù hợp và có phần thiên về an toàn.

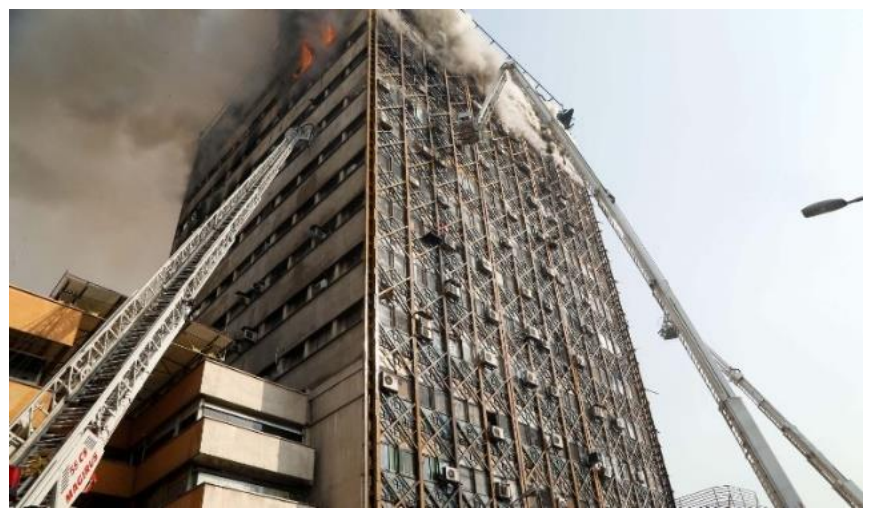

a) Toà nhà đang bị cháy

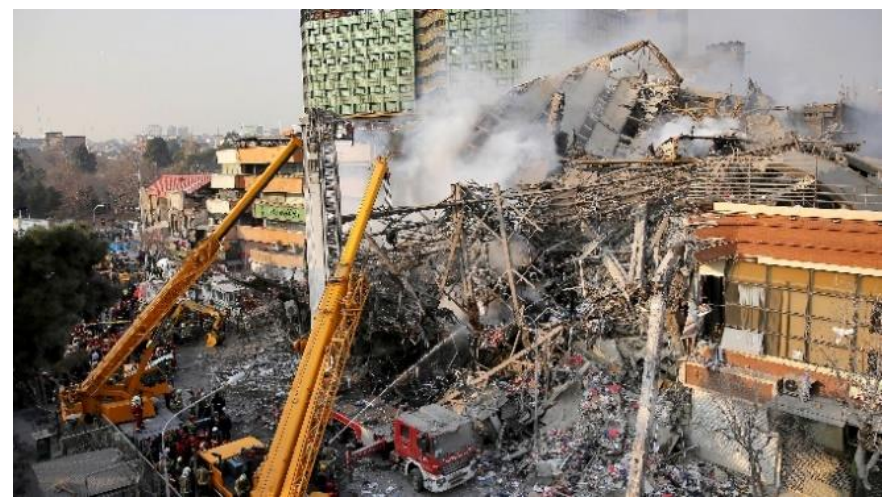

b) Tòa nhà đã bị sập do cháy

Hình 2. Tòa nhà cao tầng Plasco ở Iran bị sụp đổ do cháy (nguồn: https://www.nbcnews.com/news/world/tehran-s-iconic-plascobuilding-collapses-after-fire-iran-state-n708721)

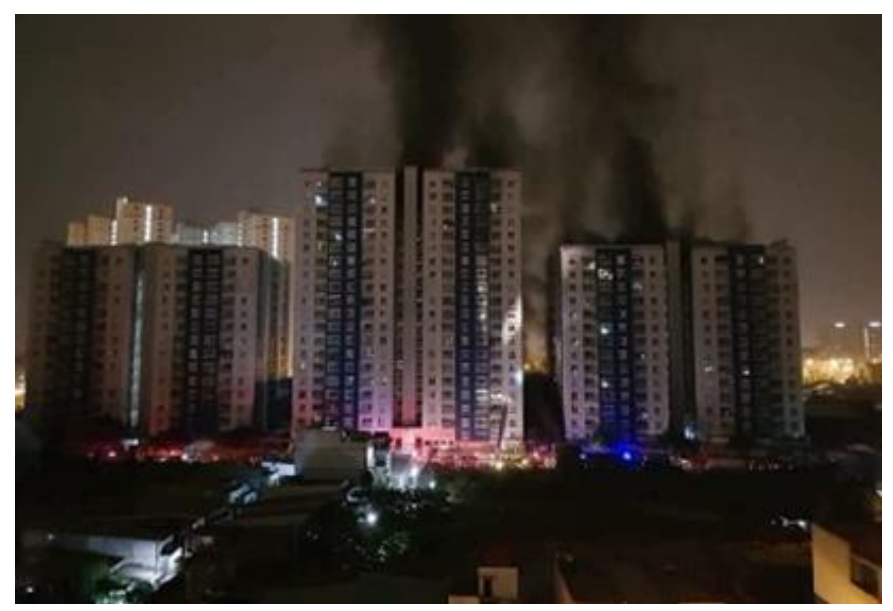

Hình 3. Chung cư Carina Plaza (Tp Hồ Chí Minh) bị cháy (nguồn: vietnamnews.vn) 
Bên cạnh các công trình nghiên cứu mô phỏng kết cấu sàn BTCT bị cháy, các nghiên cứu thực nghiệm cũng được thực hiện bởi một số tác giả. Wang và cộng sự [10] nghiên cứu thực nghiệm ứng xử của sàn BTCT nhịp liên tục chịu tác động của lửa. Tác giả đã thực hiện thí nghiệm bằng lò đốt với các tham số nghiên cứu như nhiệt độ cháy, sự phân bố nhiệt độ, chuyển vị và dạng phá hoại trong cả giai đoạn tăng nhiệt và nguội. Kết quả cho thấy rằng dạng vết nứt phụ thuộc vào điều kiện liên kết của sàn. Liên kết hàn kết hợp với bu lông sẽ làm giảm ứng suất và ngăn cản mất ổn định cục bộ. Nigro và cộng sự [11] nghiên cứu thực nghiệm ứng xử của 6 sàn bê tông cốt GFRP dưới tác dụng của lửa. Bốn sàn được thí nghiệm dưới tác dụng của tải trọng trong điều kiện đang cháy; trong khi đó, hai sàn được thí nghiệm sau cháy khi nhiệt độ đã nguội về nhiệt độ môi trường xung quanh. Mục tiêu của thí nghiệm là đánh giá khả năng chịu tải còn lại sau khi bị cháy. Kết quả thí nghiệm cho thấy rằng lớp bê tông bảo vệ và chiều dài neo của thanh GFRP có vai trò quan trọng đối với khả năng chịu lửa của sàn. Lớp bảo vệ có tác dụng bảo bệ các thanh GFRP vốn không chịu được lửa. Chiều dài neo có tác dụng ngăn cản sự suy giảm lực dích bám giữa thanh FRP và bê tông. Wang và cộng sự [12] nghiên cứu ứng xử thực nghiệm sàn BTCT tỷ lệ thực bị cháy dưới tác dụng của các tải trọng khác nhau. Nghiên cứu này tập trung vào mối quan hệ giữa lực liên kết theo phương ngang, biến dạng, sự phát triển vết nứt và sự bong tách bê tông dưới tác dụng của lửa. Lực liên kết theo phương đứng tại các góc cũng được nghiên cứu. Kết quả nghiên cứu cho thấy rằng lực dọc trong sàn có ảnh hưởng lớn đến số lượng và phương của vết nứt xuất hiện ở mặt trên của sàn trong khi chịu tác dụng của lửa. Khi sàn chỉ có liên kết ngăn cản chuyển vị theo phương mặt phẳng của sàn thì sàn có độ võng lớn hơn và mức độ phục hồi độ võng lại thấp hơn so với các sàn khác. Kết quả nghiên cứu cũng chỉ ra rằng tỷ lệ cốt thép tăng sẽ có hiệu quả trong việc ngăn cản phá hoại của sàn.

Ở Việt Nam, nghiên cứu về kết cấu bị cháy chưa được quan tâm đúng mức. Các kết quả nghiên cứu được công bố rất hạn chế. Các nghiên cứu về cháy được công bố trên các Tạp chí của Việt Nam gồm [13 - 20]. Tran và cộng sự [13] đã nghiên cứu thực nghiệm ảnh hưởng của lửa đến sự phát triển vết nứt và sự bong tách bê tông của dầm BTCT bị cháy. Trinh và Cao [14] nghiên cứu thực nghiệm về hư hại của ống thép nhồi bê tông chịu tác dụng của lửa. Ngo và Cao [15] đã nghiên cứu thực nghiệm ảnh hưởng của lửa đến dạng phá hoại của cột BTCT. Vo và Cao [16] tiến hành gia cường FRP cho cột BTCT bị cháy. Chu [17] mô phỏng cột ống thép nhồi bê tông bị cháy bằng phần mềm ANSYS. Nguyen [18] phân tích ảnh hưởng của sự bố trí cốt thép dọc tới khả năng chịu lực của cột BTCT tại nhiệt độ cao. Nguyen [19] phân tích khả năng kháng cháy của cột trong kết cấu khung BTCT. Hoang [20] mô phỏng dầm BTCT chịu tác động của lửa với sự lựa chọn phần tử cho mô hình nhiệt học trong ANSYS.

Có thể thấy rằng, các nghiên cứu về kết cấu bị cháy ở Việt Nam còn rất hạn chế. Các nghiên cứu về kết cấu sàn bị cháy được công bố còn ít, các nghiên cứu thực nghiệm càng ít hơn. Vì vậy, bài báo này trình bày nghiên cứu thực nghiệm sức chịu tải của sàn BTCT bị cháy. Thí nghiệm được thực hiện trên 9 mẫu sàn có kích thước 2000 × $750 \times$ $100 \mathrm{~mm}$ (chiều dài $\times$ chiều rộng $\times$ bề dày). Một mẫu không cháy làm mẫu đối chứng. Các mẫu sàn còn lại được chia làm 2 nhóm: mỗi nhóm có 4 mẫu sàn với thời gian cháy lần lượt là 45 phút và 75 phút. Chi tiết kết quả thí nghiệm sự ảnh hưởng của lửa đến bê tông và khả năng chịu tải của sàn $\mathrm{BTCT}$ sau khi cháy có và không có gia cường bằng FRP được trình bày trong các phần sau.

\section{Vật liệu và chế tạo mẫu}

\subsection{Vât liệu}

Các mẫu được chế tạo với thành phần cấp phối bê tông theo Bảng 1. Trong quá trình đúc mẫu sàn BTCT, tiến hành lấy 3 mẫu bê tông hình trụ đường kính $150 \mathrm{~mm}$, chiều cao $300 \mathrm{~mm}$ để xác định cường độ bê tông chịu nén thực tế, cường độ chịu nén sau 28 ngày tuổi trung bình 26,02 MPa. Cốt thép đúc mẫu là thép Việt Nhật, đường kính $\phi 10$. Lây 3 mẫu thép tiến hành thí nghiệm kéo xác định các giá trị giới hạn chảy, giới hạn bền kéo trung bình lần lượt là 335,8 MPa and 486,6 MPa.

Bảng 1.

Cấp phối bê tông chế tạo mẫu sàn thí nghiệm

\begin{tabular}{|l|l|c|c|}
\hline $\begin{array}{l}\text { Vật liệu sử } \\
\text { dụng }\end{array}$ & $\begin{array}{l}\text { Nguồn gốc vật } \\
\text { liệu }\end{array}$ & Đơn vị & $\begin{array}{l}\text { Lượng vật liệu } \\
\text { cho } \mathbf{1} \mathbf{~ m}^{\mathbf{3}} \text { bê } \\
\text { tông }\end{array}$ \\
\hline Xi măng & Long Sơn PCB50 & $\mathrm{kg}$ & 340 \\
\hline Cát & Tân Châu & $\mathrm{kg}$ & 847 \\
\hline Đá $10 \times 20 \mathrm{~mm}$ & Tân Hóa An & $\mathrm{kg}$ & 1130 \\
\hline Nước & Nước sạch & lít & 131 \\
\hline
\end{tabular}

2.2. Chế tạo mẫu

Tổng cộng có 9 mẫu sàn BTCT được chế tạo với kích thước 2000 × 750 $\times 100 \mathrm{~mm}$ đã được chế tạo. Cốt thép $\phi 10$ được dùng làm cốt dọc và ngang của sàn. Cốt dọc gồm 7 thanh $\phi 10$ bước $120 \mathrm{~mm}$. Lớp bảo vệ của cốt dọc (tính đến mép cốt thép) là $15 \mathrm{~mm}$. Cốt ngang gồm 17 thanh $\phi 10$ đặt trên cốt dọc với bước thép $123 \mathrm{~mm}$. Hình 4 trình bày kích thước và bố trí cốt thép mẫu sàn. Ba ngày sau khi đổ bê tông sàn, các mẫu sàn được bao phủ bởi một lớp cát được tưới hàng ngày để bảo dưỡng. Lớp cát giúp lưu trữ nước để bảo dưỡng bê tông phát triển cường độ.

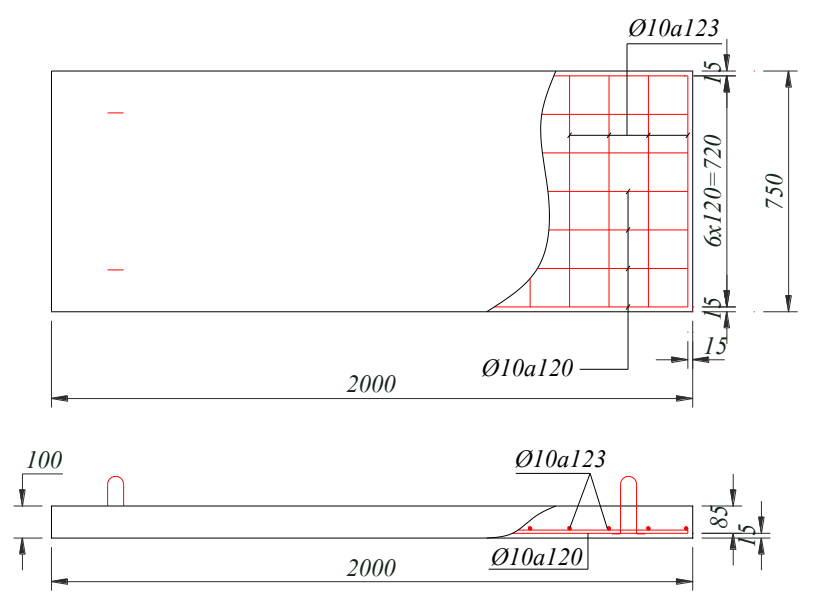

Hình 4. Kích thước và cốt thép mẩu sàn BTCT 
Mẫu được chia thành 3 nhóm mẫu thí nghiệm cháy với thời gian cháy lần lượt là 0 phút, 45 phút và 75 phút. Nhóm sàn không cháy gồm một mẫu dùng làm mẫu đối chứng. Các nhóm mẫu và thời gian cháy tương ứng được thể hiện chi tiết theo Bảng 2 . Tên các mẫu được đặt theo quy cách $\mathrm{St}-\mathrm{i}$, trong đó, $\mathrm{S}$ là kí hiệu mẫu, $\mathrm{t}$ là thời gian cháy tính theo phút và i là số thứ tự mẫu trong nhóm.

\section{Bảng 2 .}

Phân nhóm các mẫu thí nghiệm

\begin{tabular}{|l|c|c|cc|}
\hline TT & Tên mẫu & Nhóm mẫu & $\begin{array}{l}\text { Thời } \\
\text { (phút) }\end{array}$ & gian cháy \\
\hline 1 & S0 & S0 & \multicolumn{2}{|c|}{0} \\
\hline 2 & S45-1 & & & \\
\hline 3 & S45-2 & S45 & & \\
\hline 4 & S45-3 & & \\
\hline 5 & $S 45-4$ & & & \\
\hline 6 & $S 75-1$ & & & \\
\hline 7 & $S 75-2$ & S75 & \\
\hline 8 & $S 75-3$ & & \\
\hline 9 & S75-4 & & \\
\hline
\end{tabular}

\section{Thí nghiệm cháy}

Sau thời gian 28 ngày, 8 sàn BTCT được cẩu lắp đặt lên hệ khung đỡ. Tiếp theo, hồ chứa dầu với chu vi rộng hơn chu vi các mẫu sàn $50 \mathrm{~cm}$ được thi công. Sau đó, các vách tôn bao che được thi công. Vật liệu sử dụng cho thí nghiệm cháy là dầu và củi. Củi được xếp và dàn trải đều vào hồ chứa dầu. Dầu chỉ được đổ vào hồ chứa ngay trước khi đốt. Khi mồi lửa, dầu sẽ cháy trước, củi sẽ cháy sau. Trong khoảng thời gian sau khi củi cháy gần hết, một lượng dầu sẽ được tiếp từ ngoài vào. Để thực hiện được việc tiếp dầu này, dầu sẽ được chứa trong các túi nylon với thể tích chứa khoảng 1 lít dầu. Các túi dầu này sẽ được ném vào trong bể chứa đang cháy. Dầu trong túi sẽ bung ra và tự cháy. Thí nghiệm cháy thực hiện vào ban đêm nhằm quan sát rõ hơn quá trình cháy và kiểm soát tàn lửa bị bắn ra xa (nếu có). Hình 5 thể hiện quá trình thí nghiệm cháy. Nhiệt độ lớn nhất của nhóm mẫu cháy 45 phút đo được là $984,8^{\circ} \mathrm{C}$ và của nhóm mẫu cháy 75 phút là $982,0^{\circ} \mathrm{C}$. Hình 6 là các mẫu thí nghiệm sau khi đã thí nghiệm cháy.

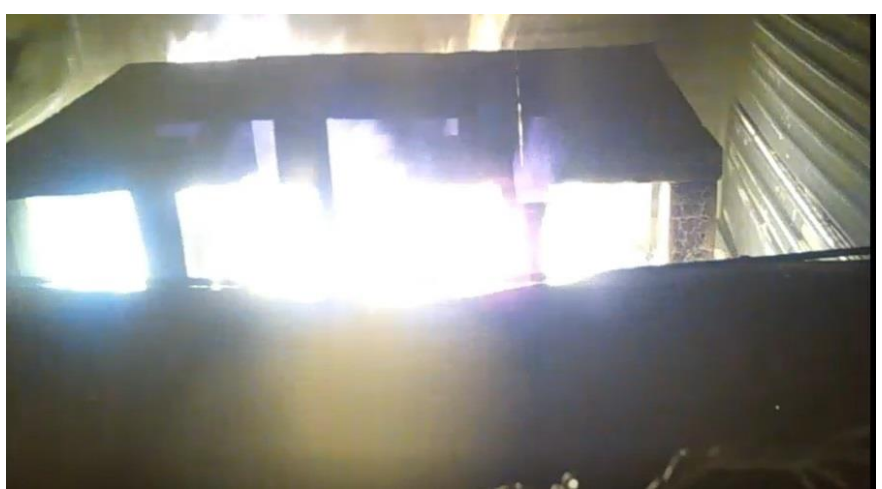

Hình 5. Thí nghiệm cháy

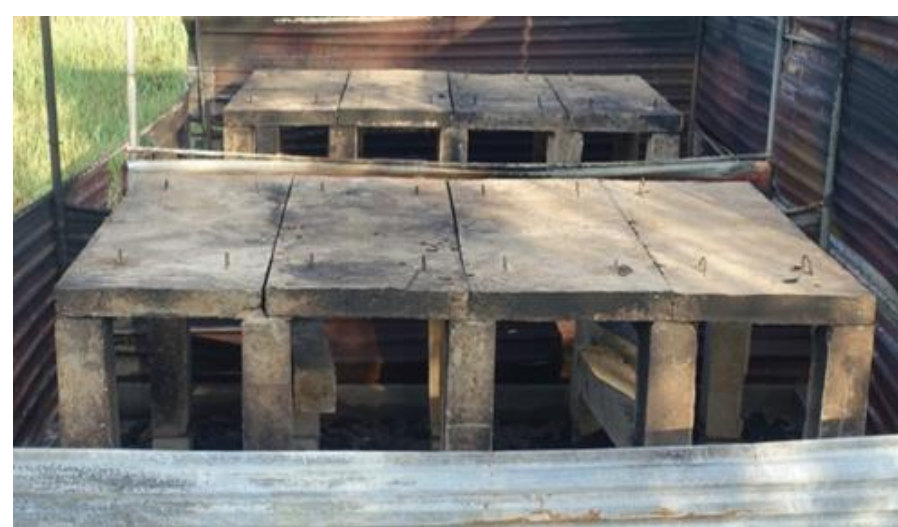

Hình 6. Các mẫu sau thí nghiệm cháy

\section{Gia cường sàn BTCT bi cháy}

Sau khi cháy, các mẫu sàn BTCT S45-3, S45-4 được gia cường $1 / 2$ lớp, bằng các dải FRP. Tổng cộng có 7 dải được dán cho mỗi sàn. Bề rộng mỗi dải là $50 \mathrm{~mm}$, chiều dài của dải là $1,5 \mathrm{~m}$. Các sàn $\mathrm{S} 75-3$ và S75-4 được gia cường bằng 1 lớp FRP. Bề rộng lớp FRP bằng bề rộng của sàn, chiều dài của lớp FRP này là $1,5 \mathrm{~m}$. Bề dày của lớp FRP là $0,167 \mathrm{~mm}$. Ba mẫu FRP được lấy để thí nghiệm kéo đo cường độ và mô đun. Cường độ và mô đun đàn hồi trung bình của 3 mẫu này lần lượt là 3757,5 MPa và 234780,2 MPa. Hình 7 thể hiện 9 bản sàn BTCT chuẩn bị cho công tác thí nghiệm gia tải.

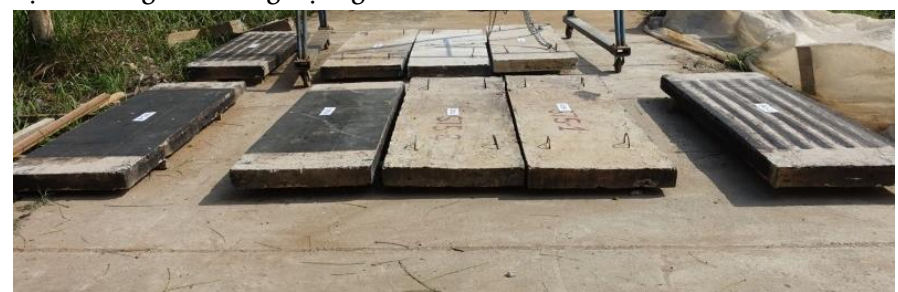

Hình 7. Các sàn BTCT chuẩn bị cho quá trình gia tải

\section{Thí nghiệm gia tải}

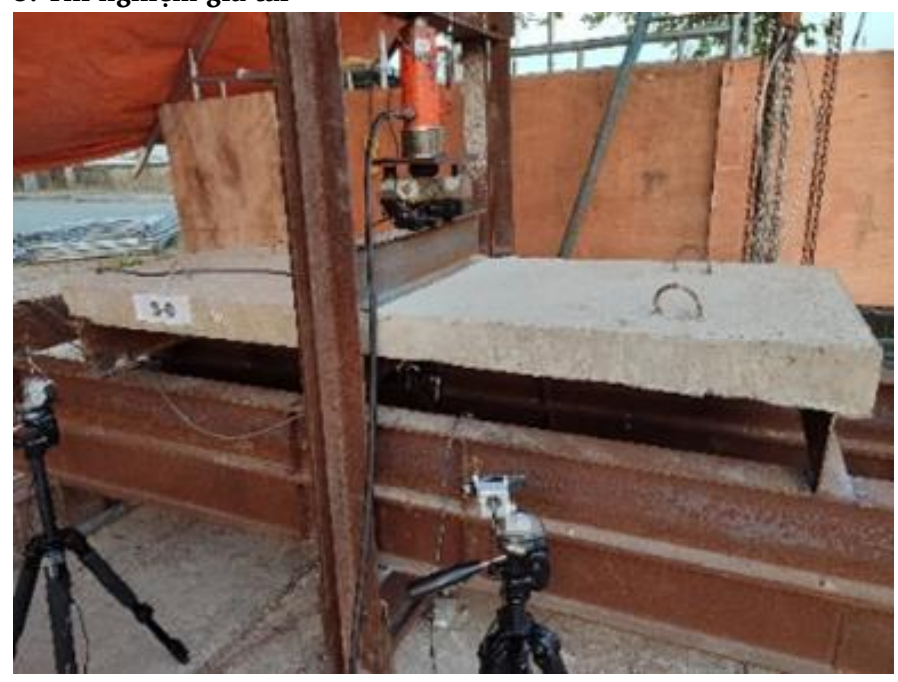

Hình 8. Thí nghiệm gia tải sàn cho sàn BTCT

Sau khi các mẫu được gia cường, các mẫu lần lượt được gia tải đến khi phá hoại. Hình 8 thể hiện sàn đầu tiên được gia tải. Khoảng cách hai gối tựa là $1,9 \mathrm{~m}$. Lực kích phân bố lên sàn thông qua thanh I 
nằm ngang. Lực kích được đo bằng load cell như có thể thấy trên Hình 8. Chuyển vị kế cũng được lắp đặt để đo chuyển vị của sàn nhằm phục vụ cho nghiên cứu khác.

\section{Kết quả thí nghiệm}

\section{1. Ảnh hưởng của lửa đến bê tông}

Sau khi cháy, màu sắc bê tông ở mặt dưới các mẫu sàn bị cháy chuyển màu rõ rệt do chịu tác động trực tiếp của lửa. Màu sắc bê tông thay đổi từ màu xám của bê tông thông thường sang màu vàng nhạt, hồng nhạt hoặc xám đen như Hình 9.

Các vết nứt chân chim xuất hiện ở mặt tiếp xúc với lửa của các mẫu sàn bị cháy. Một vài vị trí góc và cạnh bị bong tróc. Hình 10 thể hiện sự bong tróc điển hình tại góc của sàn BT bị cháy. Sự bong tróc ở các vị trí này có thể là do ứng suất nhiệt tập trung tại các góc cạnh của sàn bê tông.

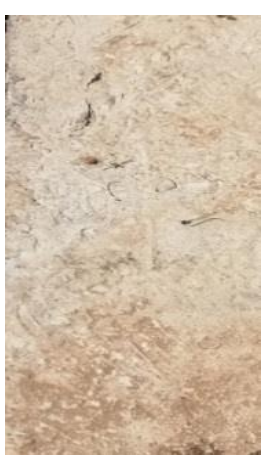

a)

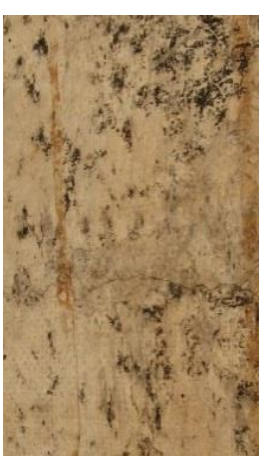

b)

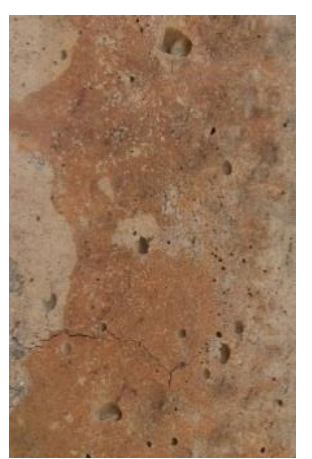

c)
Hình 9. Màu sắc sàn BTCT sau thí nghiệm cháy

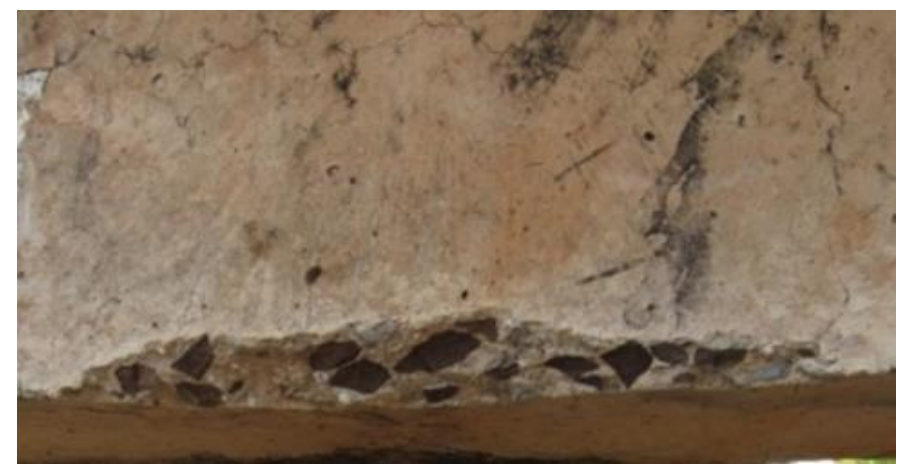

Hình 10. Sàn BTCT bị vỡ tại góc sau thí nghiệm cháy

\subsection{Khả năng chịu tải của sàn}

Khả năng chịu tải cực hạn của sàn đối chứng S0 là 34,7 kN. Khả năng chịu tải cực hạn của sàn S45-1 và S45-2 lần lượt là $32,7 \mathrm{kN}$ và $31,1 \mathrm{kN}$. So với sàn đối chứng, sức chịu tải cực hạn của các sàn S45-1 và S45-2 lần lượt giảm đi 5,8 \% và 10,4 \%. Cũng cần nhấn mạnh rằng, sự suy giảm này là sự suy giảm sau khi cháy chứ không phải trong thời gian cháy nhằm đánh giá phục vụ cho việc gia cường sau cháy. Một lý do khác nữa là việc gia cường FRP chỉ được thực hiện sau khi cháy và ở nhiệt độ thường. Sự suy giảm trong thời gian cháy (cơ - nhiệt đồng thời) là ngoài phạm vi nghiên cứu của bài báo này và là một đề tài cần được nghiên cứu thêm. Với gia cường $1 / 2$ lớp FRP, khả năng chịu tải cực hạn của các sàn $S 45-3$ và $S 45-4$ tương ứng tăng lên 52,2 kN và 49,6 kN. So với mẫu đối chứng, sức chịu tải cực hạn của sàn gia cường FRP đã tăng lên tương ứng 50,2 \% và 42,9 \%. Độ tăng trung bình cho các mẫu gia cường $1 / 2$ lớp FRP là 46,6 \%.

Chuyển sang nhóm mẫu bị cháy 75 phút, khả năng chịu tải cực hạn của mẫu $S 75-1$ và $S 75-2$ tương ứng là $33,5 \mathrm{kN}$ và $32,1 \mathrm{kN}$. So với sức chịu tải cực hạn của mẫu đối chứng, các mẫu S75-1 và S75-2 giảm lần lượt là $3,5 \%$ và $7,6 \%$. So với các mẫu $S 45$, sự suy giảm này có phần nhỏ hơn do nhiệt độ cháy của nhóm mẫu S45 có cao hơn một ít so với nhóm mẫu S75. Các mẫu sàn, sau khi bị cháy 75 phút và gia cường 1 lớp FRP, S75-3 và S75-4 có sức chịu tải cực hạn lần lượt là $59,5 \mathrm{kN}$ và $55,3 \mathrm{kN}$. So với mẫu đối chứng $\mathrm{S} 0$, sức chịu tải cực hạn của các mẫu S75-3 và S75-4 tăng lần lượt là $71,4 \%$ và 59,3 \%. Độ tăng trung bình cho các mẫu gia cường một lớp FRP là 65,4%.

Như vậy, sự suy giảm khả năng chịu tải cực hạn của các sàn sau khi bị cháy là khoảng dưới 10,5 \% có thể do cốt thép đã phục hồi cường độ sau khi để nguội. Bên cạnh đó, bê tông vùng chịu nén của các bản sàn không bị suy giảm cường độ do lửa chỉ tác dụng lên bề mặt dưới của bản sàn. Hai yếu tố này có vai trò quyết định đối với sự suy giảm không nhiều về cường độ của sàn. Gia cường FRP đã là tăng đáng kế sức chịu tải cực hạn của các bản sàn.

\section{Kết luận}

Bài báo này trình bày nghiên cứu thực nghiệm sự ảnh hưởng của lửa đến bê tông và khả năng chịu tải cực hạn của sàn BTCT sau khi cháy. Thí nghiệm được thực hiện trên 9 mẫu sàn BTCT có kích thước $2000 \times 750 \times 100$ mm. Kết quả thí nghiệm cho thấy bề mặt các mẫu sàn sau khi thí nghiệm cháy xuất hiện vết nứt chân chim. Màu sắc các mẫu này chuyển từ màu xám trước khi cháy sang màu vàng nhạt, hồng nhạt và xám đen sau khi cháy. Sàn đối chứng và sàn bị cháy không gia cường bị phá hoại uốn. Trong khi đó, các sàn gia cường FRP bị phá hoại do sự bong tách lớp FRP gia cường. Sự suy giảm khả năng chịu tải cực hạn của các sàn bị cháy nhỏ hơn 10,5 \% có thể do cốt thép đã phục hồi cường độ sau khi để nguội. Gia cường $1 / 2$ lớp FRP cho các sàn bị cháy 45 phút đã làm tăng từ 42,9 \% đến 50,2 \% khả năng chịu tải cực hạn của sàn. Gia cường 1 lớp FRP đã làm tăng từ 59,3 \% đến 71,4 \% khả năng chịu tải cực hạn của sàn bị cháy 75 phút.

\section{Lời cám ơn:}

Nhóm tác giả chân thành cảm ơn sự hỗ trợ cơ sở vật chất của Trường Đại học Xây Dựng Miền Tây và Trường Đại học Bách Khoa ĐHQG Tp. HCM trong quá trình thực hiện thí nghiệm.

\section{Tài liệu tham khảo}

[1] Huang Z (2010), The behaviour of reinforced concrete slabs in fire, Fire Safety Journal $45 \quad$ (5):271-282, doi:https://doi.org/10.1016/j.firesaf.2010.05.001

[2] Lim L, Buchanan A, Moss P, Franssen J-M (2004), Numerical modelling of two-way reinforced concrete slabs in fire, Engineering Structures, 26 (8):1081-1091, doi:http://dx.doi.org/10.1016/j.engstruct.2004.03.009.

[3] Huang Z, Burgess Ian W, Plank Roger J (2003), Modeling Membrane Action of Concrete Slabs in Composite Buildings in Fire. I: Theoretical 
Development, Journal of Structural Engineering 129 (8):1093-1102, doi:10.1061/(ASCE)0733-9445(2003)129:8(1093)

[4] Huang Z, Burgess Ian W, Plank Roger J (2003), Modeling Membrane Action of Concrete Slabs in Composite Buildings in Fire. II: Validations, Journal of Structural Engineering 129 (8):1103-1112, doi:10.1061/(ASCE)07339445(2003)129:8(1103)

[5] Lim L, Buchanan A, Moss P, Franssen J-M (2004), Computer Modeling of Restrained Reinforced Concrete Slabs in Fire Conditions, Journal of Structural Engineering 130 (12):1964-1971, doi:10.1061/(ASCE)07339445(2004)130:12(1964)

[6] Moss PJ, Dhakal RP, Wang G, Buchanan AH (2008), The fire behaviour of multi-bay, two-way reinforced concrete slabs, Engineering Structures 30 (12):3566-3573, doi:https://doi.org/10.1016/j.engstruct.2008.05.028

[7] Huang Z, Burgess IW, J. Plank R (2000), Effective stiffness modelling of composite concrete slabs in fire, Engineering Structures 22 (9):1133-1144, doi:https://doi.org/10.1016/S0141-0296(99)00062-0.

[8] Yu X, Huang Z (2008), An embedded FE model for modelling reinforced concrete slabs in fire, Engineering Structures 30 (11):3228-3238, doi:https://doi.org/10.1016/j.engstruct.2008.05.004

[9] Wang Y, Yuan G, Huang Z, Lyu J, Li Q, Long B (2018), Modelling of reinforced concrete slabs in fire, Fire Safety Journal 100:171-185, doi:https://doi.org/10.1016/j.firesaf.2018.08.005

[10] Wang Y, Dong YL, Li B, Zhou GC (2013), A fire test on continuous reinforced concrete slabs in a full-scale multi-story steel-framed building, Fire Safety 61:232-242, doi:https://doi.org/10.1016/j.firesaf.2013.08.005

[11] Nigro E, Cefarelli G, Bilotta A, Manfredi G, Cosenza E (2011), Fire resistance of concrete slabs reinforced with FRP bars. Part I: Experimental investigations on the mechanical behavior, Composites Part B: Engineering 42

(6):1739-1750, doi:https://doi.org/10.1016/j.compositesb.2011.02.025

[12] Wang Y, Yuan G, Huang Z, Lyv J, Li Z-Q, Wang T-y (2016), Experimental study on the fire behaviour of reinforced concrete slabs under combined uni-axial in-plane and out-of-plane loads, Engineering Structures 128:316332, doi:https://doi.org/10.1016/j.engstruct.2016.09.054

[13] Tran HN, Nguyen VN, Cao VV (2019), Effects of fire on cracks and spalling of reinforced concrete beams: An experimental study, Vietnam Journal of Construction 6-2019:66-70.

[14] Trinh TMN, Cao VV (2019), Experimental study on damage of concrete filled tubes exposed to fire, Vietnam Journal of Construction 6-2019:37-40.

[15] Ngo ST, Cao VV (2019), Effects of fire on concrete and the failure of reinforced concrete columns: an experimental study, Vietnam Journal of Construction 6-2019:162-166.

[16] Vo TH, Cao VV (2019), Experimental study on failure modes of fire-exposed reinforced concrete columns retrofitted by FRP, Vietnam Journal of Construction 6-2019:193-198.

[17] Chu BT (2012), Nghiên cứu thực nghiệm cột ống thép nhồi bê tông trong điều kiện cháy, Tạp Chí Khoa Học Công Nghệ Xây Dựng 2(2012).

[18] Nguyen TT (2019), Ảnh hưởng của sự bố trí cốt thép dọc tới khả năng chịu lực của cột bê tông cốt thép tại nhiệt độ cao, Vietnam Journal of Construction 2019:141-144.

[19] Nguyen TT (2019), Khả năng kháng cháy của cột trong kết cấu khung bê tông cốt thép, Vietnam Journal of Construction 2019:53-57.

[20] Hoang GA (2017), Dầm bê tông cốt thép chịu tác động của lửa - lựa chọn phần tử cho mô hình nhiệt học trong ANSYS, Tạp Chí KHCN Xây Dựng, 4:917. 